\title{
The Effectiveness of Child-Centered Play Therapy Training in Malaysia
}

\author{
$\mathrm{Ku}$ Suhaila Ku Johari ${ }^{1}$, Mary Alice Bruce ${ }^{2} \&$ Mohamad Isa Amat ${ }^{3}$ \\ ${ }^{1}$ Faculty of Education, Universiti Kebangsaan Malaysia, Selangor, Malaysia \\ ${ }^{2}$ College of Education, University of Wyoming, Wyoming, United States \\ ${ }^{3}$ Fakulti Kepimpinan \& Pengurusan, Universiti Sains Islam Malaysia, Negeri Sembilan, Malaysia \\ Correspondence: Ku Suhaila Ku Johari, Faculty of Education, Universiti Kebangsaan Malaysia, 43600 UKM \\ Bangi, Selangor, Malaysia. E-mail:ku_ukm@yahoo.com
}

Received: November 17, 2013 Accepted: February 23, 2014 Online Published: March 31, 2014

doi:10.5539/ass.v10n7p221

URL: http://dx.doi.org/10.5539/ass.v10n7p221

\begin{abstract}
Play therapy in Malaysia is still in the early stages of development. This study investigated the effectiveness of Child-Centered Play Therapy by conducting 3-day training sessions in different part of Malaysia for a total of 116 participants including mental health students and practitioners. Four research questions guided this study in exploring the differences on the three subscales: attitude, knowledge, and skills in play therapy. A repeated measure design was used for the pre-test and post-test instruments. Results indicated statistically significantly differences between pre and post tests on the all subscales. In comparing students and practitioners, result indicated no statistically significantly differences for all subscales on the pre and post tests. However, there was a statistically significantly difference between participants with and without previous play therapy experiences on the knowledge and skills subscales for the pre and post tests. In addition, a correlation design show there was statistical significance between the relationships among the subscales. For future research, a design incorporating random assignment and a control group as well as differencing lengths of training session are planned.
\end{abstract}

Keywords: counseling, play therapy training, child-centered play therapy

\section{Introduction}

Play is a cherished part of childhood, and play also can contribute towards many benefits in children's lives. In the mental health profession, play therapy is acknowledged educationally and clinically as an effective intervention to improve the mental health of child clients (Landreth, 2012). However, play therapy requires sufficient and appropriate training to acquire the skills needed for its practice (Kao, 2005; Kranz, \& Lund, 1994; Kranz, Lund, \& Kottman, 1996; Landreth, 2012). Play therapy has been growing very quickly due to an increasing awareness of children's mental health care needs (Bratton et al., 2005). Hence, more play therapists are needed to meet the needs of child clients (Porter, Hernandez-Reif, \& Jessee, 2009). Moreover, many researchers have addressed the effectiveness of Child-Centered Play Therapy (CCPT) training in helping play therapists improve their attitude, knowledge, and skills (Homeyer \& Rae, 1999; Hunt, 2006; Kagan \& Landreth, 2009; Kao \& Chang, 2007; Kao \& Landreth, 1997; Lindo et al., 2012; Shen, 2002; Shen \& Herr, 2003). Their findings have shown positive impacts on the counseling profession and children with difficulties. Studies conducted in developing countries suggest that CCPT has contributed significant improvement to the mental health profession in general, and play therapy in particular in those nations.

\section{Background}

Many studies of various types of play therapy training have been conducted (e.g., Kagan \& Landreth, 2009; Kao \& Chang, 2007; Hunt, 2010). Trainings demonstrate benefits for mental health professionals including practitioners, counselors, school counselors, and graduate counseling students, who work closely with children in support of their well-being.

Bratton et al. (1993) investigated the effectiveness of training by conducting an intensive three-day play therapy supervision. The therapist and participants reported many areas of self-improvement through this training with changes occurring rapidly such as self-awareness, confidence, therapeutic skills, and understanding of the play therapy process. In addition, Kao and Landreth (1997) studied long-term play therapy training in the form of a 
semester-long course for graduate students specializing in working with children. Findings of the study indicated that trainees' attitudes toward and knowledge of children improved, as did their confidence in applying play therapy skills. Another study, by Homeyer and Rae (1998), evaluated the impact of the length of play therapy training. The findings showed that the varied lengths of the courses and the configuration of class meetings were not significant factors in helping students change. Regardless of the training format whether short or long term, their experiences as trainees in play therapy significantly affected them in a positive manner. Recently, Lindo et al., (2012), investigated the impact of training on attitude, knowledge, and skills for graduate counseling students throughout a 15-week semester play therapy course. The findings indicated this course positively impacted the counseling graduate students' attitudes toward themselves, toward children, and towards play therapy, while advancing their knowledge and skills in play therapy.

Child-Centered Play Therapy training for mental health professionals also has been applied in other countries. For instance, Kagan and Landreth (2009) studied a short-term, two-day play therapy training for teachers and school counselors in a school district in Northern Israel. The research findings indicated that short-term training was significantly effective in increasing teachers' and school counselors' knowledge, but there were no significant differences on the scores of attitude and skills of the child-centered play therapy, perhaps due to the time constraint. Another study was done in Australia by Hunt (2010) to evaluate the impact of play at children's residential care settings. The study showed that play can increase emotional awareness and have therapeutic value for children. The care workers reported that the training was effective in helping them build relationships and a better understanding of children's issues and problems.

Hunt (2006) also conducted Child-Centered Play Therapy training in Kenya and Tanzania, East Africa. After the training, the participants indicated that their awareness and understanding of the therapeutic power of play had increased. In Japan, there was concern about the needs of play therapy, play specialists, and play therapy training in Japanese children's wards (Tanaka et al., 2010). The results of the study found that 81 percent of participants agreed that play specialists are needed in helping children in hospital wards. Shen (2002) studied in a group format at a rural elementary school in Taiwan. The relationship between the children and the counselor helped to decrease the level of anxiety because of the sense of safety, security, permissiveness, and acceptance by the counselor, all based on the child-centered approach.

Play therapy in Malaysia is still in an early stage of development and used primarily by several counseling practitioners and educators who were trained from other countries. They also have initiated their own learning by taking play therapy training courses in private organizations overseas to enhance their skills. However, these kinds of opportunities are limited because of the availability and high cost. Currently, several public university in Malaysia have established dedicated play therapy rooms used by their students as part of their counseling work in child and family courses. Some students are implementing experiential techniques related to play therapy such as drawing and storytelling. As a developing country, Malaysia needs to overcome its own limitations in play therapy by establishing systematic quality training based on a firm theoretical foundation. In addition, a professional association for play therapy is needed in order to organize the development of play therapy especially related to high level training and accreditation.

Based on previous studies, the researchers believe many benefits can emerge from this study that will help shape plans to strengthen the counseling profession in Malaysia. Specifically, the study may prompt efforts to establish a Malaysian play therapy association and a center for play therapy. In addition, this study may encourage the inclusion of play therapy courses in undergraduate and graduate counseling programs and highlight the need for training more play therapists as they work in various settings. However, the main purpose of this study was to evaluate the effectiveness of Child-Centered Play Therapy training among mental health students and practitioners in Malaysia. The specific objectives of the training were to: 1) increase positive attitudes toward children, 2) expand play therapy knowledge, and 3) enhance the play therapy skills of students and practitioners who participate in the helping professions in Malaysia.

\section{Research Questions}

This was a study of Child-Centered Play Therapy (CCPT) training conducted for mental health professionals in Malaysia for both students and practitioners. The research questions for this study were the following: (1) What are the differences between pre-tests and post-tests on attitude, knowledge, and skills for the general group of participants in the CCPT training in Malaysia? (2) What are the differences between pre-tests and post-tests on attitude, knowledge, and skills of the specific categories of students as compared to practitioners in the CCPT training in Malaysia? (3) What are the differences between pre-tests and post-tests on attitude, knowledge, and skills participants who had previous experience attending play therapy training and who those who had no 
previous play therapy training? (4) What are the relationships between attitude, knowledge, and skills for the general group of participants in the CCPT training in Malaysia?

\section{Methodology}

This study used a within-group experimental, repeated measure design (Creswell, 2008). The same participants and measurements were used for the pre-test and post-test instruments. The intent of this design was to assess any changes among students and practitioners in the mental health profession in Malaysia resulting from their CCPT training.

\subsection{Participants}

The participants in this study were counseling students (undergraduate, masters and doctoral) and practitioners in Malaysia. The counseling students and practitioners who volunteered to participate in this study registered through International Malaysian Counseling Association (PERKAMA International). In addition, the participants were required to meet the following criteria to be eligible for participation: each must (a) be enrolled as a student in a mental professional program (undergraduate, master's or doctoral) or be a practitioner in the mental health profession; (b) agree to participate in a three-day training; (c) agree to complete pre- and post- instruments, and (d) sign a consent form. The three-day training events were conducted for the convenience of participants from thirteen states (Johor, Kedah, Kelantan, Melaka, Negeri Sembilan, Pahang, Perak, Perlis, Pulau Pinang, Sabah, Sarawak, Selangor, and Terengganu) and one federal territory (Wilayah Persekutuan). From all of the states, the participation was divided into six zones in Malaysia: Central, North, North Borneo Island, East, South, and South Borneo Island. In addition, the researcher collaborated with seven training facilitators, who had experience in the CCPT. For their work in this study, the facilitators had been intensively trained by the researcher to supervise and guide participants during group activities and role playing.

\subsection{Procedures}

The training was designed as a 3-day session encompassing various learning experiences including lectures, discussions, readings, observation of the instructors' and peers' play therapy sessions, live demonstrations, and role playing with the instructor and peers. At the beginning of the training, participants were given a toy kit and reading materials for their personal use. Each toy kit included samples of all types of toys suggested by Landreth (2012). These participants voluntarily completed the Play Therapy Attitude-Knowledge-Skills Survey (PTAKSS) instrument twice, before and after the three-day training. The participants who completed the instrument in this study received a certificate of participation.

\subsection{Instrument}

The PTAKSS was revised from its original version (Kao \& Landreth, 1997) to a Chinese version by Kao (Kao \& Chang, 2007). She revised the original version of PTAKSS because of inconsistency in the attitude scale (Cronbach's Alpha 0.73). Currently, it is an effective tool for use by the counseling profession, especially in Taiwan (Kao \& Chang, 2007). The PTAKSS revised version (Chinese language) was translated into the Malay language using back-to-back translation procedures. The first researcher revised several items in the instrument based on the training module for this current study. The overall number of items is sixty-one (61) items. As a result, (1) the attitude scale is twenty-four (24) items; (2) the knowledge scale is fourteen (14) items, and (3) the skills scale is twenty-three (23) items. The reliability of pre- and post-tests on the Play Therapy Attitude-Knowledge-Skills Survey (PTAKSS), Malay language, is excellent, ranging from .941 to .981, as seen in Table 1.

Table 1. Pre- and post-test reliability using the play therapy attitude-knowledge-skills survey (PTAKSS), Malay language $(\mathrm{N}=116)$

\begin{tabular}{lll}
\hline Scale & Pre-Test & Post-Test \\
\hline Attitude & .941 & .954 \\
Knowledge & .953 & .949 \\
Skills & .981 & .976 \\
\hline
\end{tabular}

\subsection{Data Analysis}

In this study, the researcher utilized SPSS for the purpose of data analysis. Descriptive analysis was used to examine the demographic information. This analysis indicated the means, percentages, standard deviations, and 
ranges of scores for the variables. The Repeated-Measures Analysis of Variance was used to evaluate any differences that were present, and the Pearson Correlation Coefficient to assess the relationship among subscales (Green \& Salkind, 2008).

\section{Results}

\subsection{Demographic Characteristics}

A descriptive analysis was used to explore participants' background including race, age, level of education, status as a mental health professional whether student or practitioner and previous play therapy training experience. See Table 2.

Table 2. Demographic characteristics of group participants $(\mathrm{N}=116)$

\begin{tabular}{|c|c|c|}
\hline Demographic & $\mathrm{N}$ & $\%$ \\
\hline \multicolumn{3}{|l|}{ Race } \\
\hline Malay & 97 & 83.6 \\
\hline Chinese & 12 & 10.3 \\
\hline Melanau & 3 & 2.6 \\
\hline Bidayuh & 3 & 2.6 \\
\hline Kenyah & 1 & 0.9 \\
\hline \multicolumn{3}{|l|}{ Age } \\
\hline $20-29$ & 61 & 52.6 \\
\hline $30-39$ & 32 & 31.0 \\
\hline $40-49$ & 12 & 10.3 \\
\hline $50-59$ & 7 & 6.0 \\
\hline \multicolumn{3}{|c|}{ Level of Education - Degrees } \\
\hline Baccalaureate & 63 & 54.3 \\
\hline Master's & 41 & 35.3 \\
\hline Doctoral & 12 & 10.3 \\
\hline Status of & Health & \\
\hline \multicolumn{3}{|l|}{ Professional } \\
\hline Student & 31 & 26.7 \\
\hline Practitioner & 85 & 73.3 \\
\hline \multicolumn{3}{|c|}{ Previous Play Therapy Training } \\
\hline Yes & 38 & 32.8 \\
\hline No & 78 & 67.2 \\
\hline
\end{tabular}

\subsection{Research Question 1}

Three dependent samples $t$-tests were conducted to evaluate whether the general group of participants in the 3-day Child-Centered Play Therapy training in Malaysia improved their attitude, knowledge, and skills scores on the Play Therapy Attitude-Knowledge-Skills Survey comparing before and after the training. The results showed the mean scores for all three subscales, attitude, knowledge, and skills on pre and post tests for the general group of participants indicated statistically significant gains from the pre test to the post test. The effect size was moderate for attitude and strong for knowledge and skills. See Table 3. 
Table 3. Dependent samples t-test on the play therapy attitude-knowledge-skills survey $(\mathrm{N}=116)$

\begin{tabular}{|c|c|c|c|c|c|c|}
\hline \multirow{2}{*}{ Scale } & \multicolumn{2}{|c|}{ Mean $\quad(\mathrm{SD})$} & \multirow{2}{*}{$\mathrm{df}$} & \multirow{2}{*}{$\mathrm{t}$} & \multirow{2}{*}{$\mathrm{p}$} & \multirow{2}{*}{$\mathrm{d}$} \\
\hline & Pre & Post & & & & \\
\hline Attitude & $4.11(.54)$ & $4.41(.50)$ & 115 & 7.47 & $\mathrm{p}<.001$ & .69 \\
\hline Knowledge & $3.03(.84)$ & $4.27(.50)$ & 115 & 18.50 & $\mathrm{p}<.001$ & 1.72 \\
\hline Skills & $2.80(.79)$ & $4.03(.53)$ & 115 & 19.32 & $\mathrm{p}<.001$ & 1.79 \\
\hline
\end{tabular}

Overall, the participants in the training demonstrated significant improvement in their attitude, knowledge, and skills related to the Child-Centered Play Therapy after the 3-day training session. Knowledge had the greatest improvement (1.24), followed by skills (1.23), and attitude (0.30). See Figure 1.

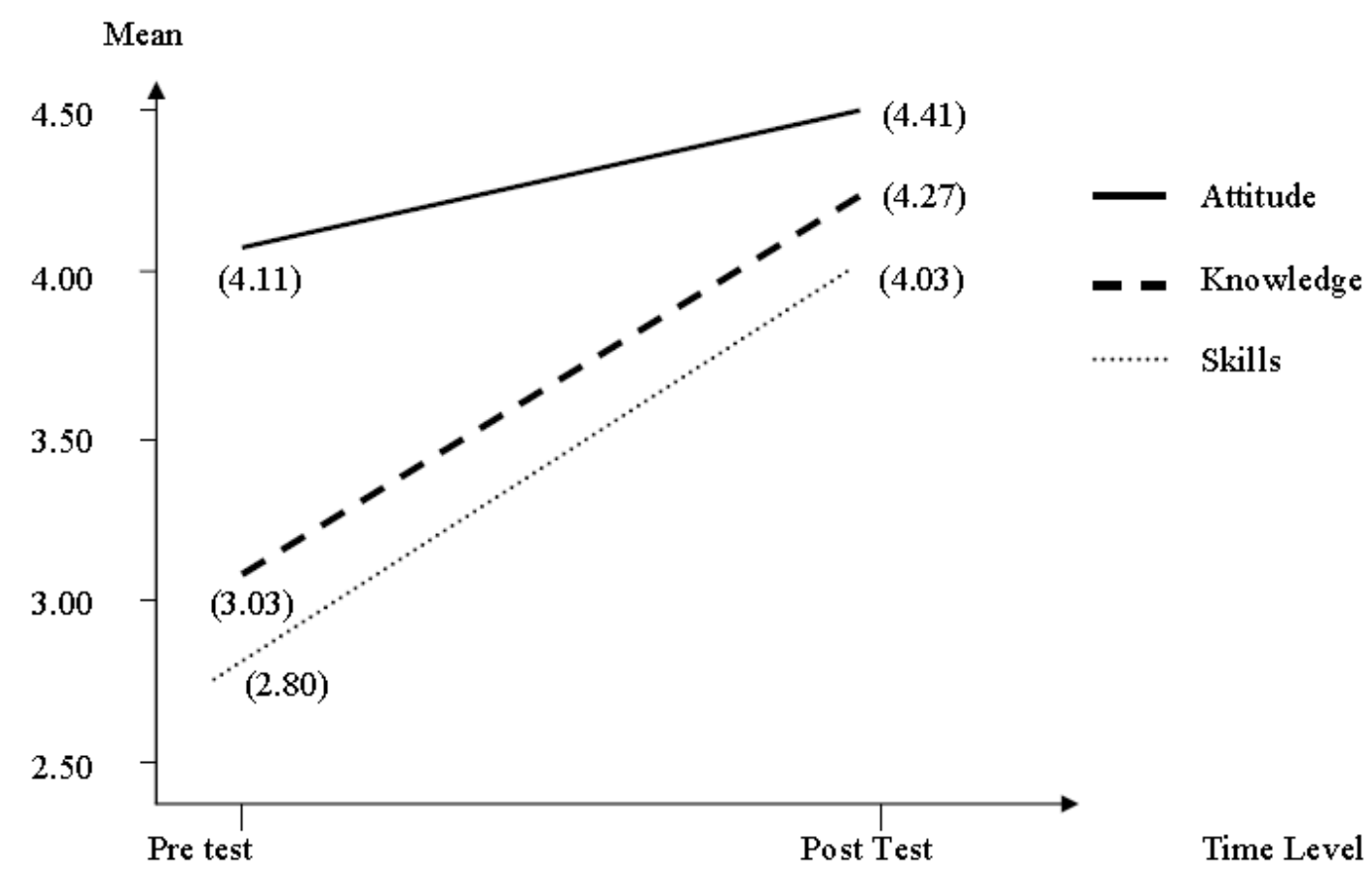

Figure 1. Attitude, knowledge, and skills scales on the pre and post test

\subsection{Research Question 2}

Three two-way repeated measures ( 2 X 2) ANOVA were conducted to evaluate attitude, knowledge, and skills scores from the Play Therapy Attitude-Knowledge-Skills Survey during the 3-day training session. There were two types of participants, mental health students and practitioners (Group), and two levels of tests, pre and post (Time). See Table 4. 
Table 4. Mean and standard deviations for group (students and practitioners) for the time (pre and post) on the play therapy attitude-knowledge-skills survey $(\mathrm{N}=116)$

\begin{tabular}{lllll}
\hline Scale & $\mathrm{N}$ & \multicolumn{2}{l}{ Mean (SD) } & Mean Difference \\
\cline { 3 - 4 } & & Pre & Post & \\
\hline Attitude & & & & .26 \\
Students & 31 & $4.00(.61)$ & $4.26(.51)$ & .31 \\
Practitioners & 85 & $4.16(.50)$ & $4.47(.49)$ & .30 \\
Total & 116 & $4.11(.54)$ & $4.41(.50)$ & \\
Knowledge & & & & 1.38 \\
Students & 31 & $2.79(.91)$ & $4.17(.559)$ & 1.19 \\
Practitioners & 85 & $3.12(.80)$ & $4.31(.472)$ & 1.24 \\
Total & 116 & $3.03(.84)$ & $4.27(.498)$ & 1.17 \\
Skills & & & & 1.26 \\
Students & 31 & $2.65(.74)$ & $3.82(.59)$ & 1.23 \\
Practitioners & 85 & $2.85(.81)$ & $4.11(.49)$ & \\
Total & 116 & $2.80(.79)$ & $4.03(.53)$ & \\
\hline
\end{tabular}

The main effect of time (pre test to post test) was significant for all three subscales: attitude, $F(1,114)=41.90$; knowledge, F $(1,114)=289.59$; and skills, $\mathrm{F}(1,114)=280.89$, as discussed in Research Question 1. The interaction effect of time by group was not significant for any of the subscales: attitude, $\mathrm{F}(1,114)=.057$; knowledge, $F(1,114)=1.65$; and skills, $F(1,114)=0.39$. Thus, results show there was no difference between mental health students and practitioners on changes in attitude, knowledge, and skills from pre test to post test. See Table 5 .

Table 5. Two-way repeated-measures ANOVA for group (students and practitioners) for the time (pre and post) on the play therapy attitude-knowledge-skills survey $(\mathrm{N}=116)$

\begin{tabular}{lcclll}
\hline Scale & df & SS & MS & F & $\mathrm{p}$ \\
\hline Attitude & & & & & \\
Pre and Post (Time) & 1 & 3.865 & 3.865 & 41.902 & $\mathrm{p}<.001$ \\
Group X Time & 1 & 0.005 & 0.005 & 0.057 & $\mathrm{p}>0.10$ \\
Knowledge & & & & & \\
Pre and Post (Time) & 1 & 75.059 & 75.059 & 298.588 & $\mathrm{p}<.001$ \\
Group X Time & 1 & 0.429 & 0.429 & 1.654 & $\mathrm{p}>0.10$ \\
Skills & & & & & \\
Pre and Post (Time) & 1 & 67.070 & 67.070 & 280.886 & $\mathrm{p}<.001$ \\
Group X Time & 1 & 0.093 & 0.093 & 0.391 & $\mathrm{p}>0.10$ \\
\hline
\end{tabular}

These findings show that both mental health students and practitioners had comparable gains in their scores on attitude, knowledge, and skills for pre and post test.

\subsection{Research Question 3}

Three two-way repeated measures $(2 \mathrm{X} 2)$ ANOVA were conducted to evaluate the attitude, knowledge, and skills scores from Play Therapy Attitude-Knowledge-Skills Survey, during the 3-day training session. There were two types of participants, ones who had had previous experience and ones who had had no previous experience attending play therapy training. See Table 6. 
Table 6. Mean and standard deviations for group (participants who had previous play therapy experience and who had no previous play therapy experience) for the time (pre and post) on the play therapy attitude-knowledge-skills survey ( $\mathrm{N}=116)$

\begin{tabular}{lllll}
\hline Scale & $\mathrm{N}$ & \multicolumn{2}{l}{ Mean (SD) } & Mean Difference \\
\cline { 3 - 4 } & & Pre & Post \\
\hline Attitude & & & & \\
With Experience & 38 & $4.25(.38)$ & $4.48(.48)$ & .23 \\
Without Experience & 78 & $4.05(.59)$ & $4.38(.51)$ & .33 \\
Total & 116 & $4.11(.54)$ & $4.41(.50)$ & .30 \\
Knowledge & & & & \\
With Experience & 38 & $3.44(.79)$ & $4.37(.53)$ & .93 \\
Without Experience & 78 & $2.83(.79)$ & $4.22(.48)$ & 1.39 \\
Total & 116 & $3.03(.84)$ & $4.27(.50)$ & 1.24 \\
Skills & & & & \\
With Experience & 38 & $3.25(.67)$ & $4.18(.59)$ & .93 \\
Without Experience & 78 & $2.58(.75)$ & $3.96(.49)$ & 1.38 \\
Total & 116 & $2.80(.79)$ & $4.03(.53)$ & 1.23 \\
\hline
\end{tabular}

The main effect of time (pre test to post test) was significant for all three subscales: attitude, $\mathrm{F}(1,114)=43.76$; knowledge, F $(1,114)=287.98$; and skills, $\mathrm{F}(1,114)=316.41$, as discussed in Research Question 1. The interaction effect of time by group was not significant on the attitude scale, $F(1,114)=1.413$. However, there were significant gains in knowledge, $\mathrm{F}(1,114)=11.48$ and skills, $\mathrm{F}(1,114)=12.12$.

On the attitude scale, the results showed no differences in pre and post training scores between participants with and without previous experience. On the other hand, the results showed differences between these two groups in their gain on knowledge scores, between pre and post training. The pre and post test mean for participants without previous experience was greater than the mean for participants with previous experience. Thus the knowledge gain for participants without previous experience was significantly greater than that of participants with previous experience. In addition, a dependent samples t-test was conducted to follow-up the significant differences on the knowledge scale of the participants with and without previous experiences in play therapy training, to test the gain from pre to post for each of the two groups. The results indicated a significant difference on their gain for pre test and post test between participants with previous play therapy training experience (pre, $\mathrm{M}=3.44$, post, $\mathrm{M}=4.37), \mathrm{t}(37)=8.50, \mathrm{p}<.001$ and those without previous play therapy training experience (pre, $\mathrm{M}=2.83$, post, $\mathrm{M}=4.22$ ), $\mathrm{t}(77)=17.58, \mathrm{p}<.001$.

Similar to the knowledge scale, there was a difference between these two groups in their changes in scores on skills from pre to post training. The gain for participants without previous experience on pre and post test was greater than the mean for participants with previous experience. Therefore, the skills for participants without previous experience were significantly greater than that of the participants with previous experience. In addition, a dependent samples t-test was conducted to follow-up the significant interaction of the skills scale on the groups of participants with and without previous experience, to test the gain from pre to post for each of the two groups. The results indicated a significant difference on their gain for pre test and post test between the participants with previous play experience (pre, $\mathrm{M}=3.24$, post, $\mathrm{M}=4.18$ ), $\mathrm{t}(37)=10.32$, $\mathrm{p}<.001$ and those without it (pre, $\mathrm{M}=$ 2.58 , post, $\mathrm{M}=3.96), \mathrm{t}(77)=17.42, \mathrm{p}<.001$. This shows that participants without previous play therapy experience had greater improvement on knowledge and skills scales than those without such experience. See Table 7. 
Table 7. Two-way repeated-measures ANOVA for group (participants who had had previous play therapy experience and those who had not) for the time (pre and post) on the play therapy attitude-knowledge-skills survey $(\mathrm{N}=116)$

\begin{tabular}{lcllll}
\hline Scale & df & SS & MS & F & $\mathrm{p}$ \\
\hline Attitude & & & & & \\
Pre and Post (Time) & 1 & 3.989 & 3.989 & 43.756 & $\mathrm{p}<.001$ \\
Group X Time & 1 & 0.129 & 0.129 & 1.413 & $\mathrm{p}>0.10$ \\
Knowledge & & & & & \\
Pre and Post (Time) & 1 & 68.795 & 768.795 & 287.979 & $\mathrm{p}<.001$ \\
Group X Time & 1 & 2.743 & 2.743 & 11.483 & $\mathrm{p}<.001$ \\
Skills & & & & & \\
Pre and Post (Time) & 1 & 68.526 & 68.526 & 316.409 & $\mathrm{p}<.001$ \\
Group X Time & 1 & 2.625 & 2.625 & 12.120 & $\mathrm{p}<.001$ \\
\hline
\end{tabular}

\subsection{Research Question 4}

A correlation coefficient was computed among pre and post tests on the attitude, knowledge, and skills subscales of the Play Therapy Attitude-Knowledge-Skills Survey. The results show there is statistical significance for all relationships between subscales in this study.

Pre-test results indicated weak correlations between the attitude and knowledge scale $(\mathrm{r}=.25)$, and the attitude and skills scale $(\mathrm{r}=.22)$. Nevertheless, there is a strong correlation between the knowledge and skills scales ( $\mathrm{r}$ $=.84)$. Furthermore, in the post test, there was moderate correlation between attitude and knowledge $(\mathrm{r}=.53)$, and between attitude and skills scale $(\mathrm{r}=.53)$. Meanwhile, there was a strong relationship between knowledge and skills $(\mathrm{r}=.81)$. See Table 8 .

Table 8. Pre- and post test correlation coefficients on the play therapy attitude-knowledge-skills survey $(\mathrm{N}=116)$

\begin{tabular}{|c|c|c|c|c|c|c|}
\hline & \multicolumn{2}{|c|}{ Attitude } & \multicolumn{2}{|c|}{ Knowledge } & \multicolumn{2}{|l|}{ Skills } \\
\hline & Pre & Post & Pre & Post & Pre & Post \\
\hline \multicolumn{7}{|l|}{ Attitude } \\
\hline Pre & --- & $.66^{* *}$ & $.25 * *$ & $.43 * *$ & $.22 *$ & $.42 * *$ \\
\hline Post & & --- & $.25 * *$ & $.53^{* *}$ & $.19 *$ & $.53 * *$ \\
\hline \multicolumn{7}{|c|}{ Knowledge } \\
\hline Pre & & & --- & $.52 * *$ & $.84 * *$ & $.55^{* *}$ \\
\hline Post & & & & --- & $.47 * *$ & $.81 * *$ \\
\hline \multicolumn{7}{|l|}{ Skills } \\
\hline Pre & & & & & --- & $.51 * *$ \\
\hline Post & & & & & & --- \\
\hline
\end{tabular}

** Correlation is significant at the .01 level (2-tailed).

* Correlation is significant at the .05 level (2-tailed).

These results showed that knowledge and skills have a stronger relationship between pre and post tests than for attitude. This suggests that in order to perform skills effectively in practice, it is more important to have sufficient knowledge than simply a positive attitude.

This finding emphasized that the knowledge element had a strong relationship with the skills element in both the pre- and post tests. During the 3-day training, presentations were grouped into several main topics. The trainer typically started the learning process with a lecture; this was followed by practice and discussion. These results indicated that participants realized the need for skill improvement. 


\section{Discussion}

\subsection{Attitudes, Knowledge, and Skills}

This study demonstrated that the 3-day training session effectively improved participants' attitude, knowledge, and skills. As play therapy is a new approach in Malaysia, it is logical to conclude that the play therapy training was beneficial for the participants by effectively increasing their knowledge. Mental health practitioners, particularly those who work with children, are looking to this kind of training opportunity to enhance their competency. The participants spent adequate time to practice play therapy skills by using toys and role plays with peers and the instructor. The 3-day training also integrated knowledge and skills with practice. Participants experienced a variety of experiential activities including role play, simulation, and reflective discussions. These activities appear to have been effective learning experiences, enhancing participants' positive attitude toward children and play therapy even beyond their initial interest in the process. This shows the importance of offering appropriate, practical, and experiential learning activities in the training (Lindo et al., 2012).

Moreover, researchers explored the effectiveness of the 3-day Child-Centered Play Therapy training for two different groups of participants: mental health students and practitioners. However, there were no differences between the groups in gains on scores in attitude, knowledge, and skills throughout the training. This training provided the same overall consequence for both groups even though practitioners had more general working experience than students. This is consistent with the fact that play therapy is a new field in Malaysia.

In comparing the participants with previous play therapy experience and participants without previous play therapy experience, the participants without previous play therapy training had higher gain in their scores on the pre and post tests for all subscales, attitude, knowledge, and skills than the participants who with previous play therapy training. However, there was no difference in their gains on attitude scores for both groups. It could be that all participants came to the training with a positive attitude, perhaps because they all were volunteers.

This study further evaluated the relationship between attitude, knowledge, and skills on pre as well as post tests for the training participants. On the pre test, attitude did not show much relationship to the level of knowledge and skills. However, there was a strong relationship between the participants' level knowledge and skills. Knowledge in play therapy can have a positive relationship on play therapy skills. On the post-test, the relationship between attitude with knowledge and attitude with skills slightly strengthened into a moderate correlation. Moreover, similar to the pre test, knowledge and skills had a strong correlation for the post test. Therefore, training strengthens the connections among attitude, knowledge, and skills in play therapy, producing a more competent play therapist. This also shows how important knowledge is as a foundation for skill in practicing play therapy effectively. It is crucial for mental health professionals to have proper training to enhance their capability in play therapy and to strengthen their competence as mental health professionals.

In addition, participants also provided written feedback on aspects of the training that can be improved. Many of them suggested that the training module should be longer than 3 days and also include fewer participants. This is very reasonable considering this training emphasized more experiential learning by having intensive skill practice and role plays. Participants also offered ideas about facilities, space, and fees. In addition, participants also requested more play therapy training opportunities in the future. Additional training days or time suggested the need to have play therapy courses in university programs, something which is very rare in Malaysia at this time. All participant feedback on this question proved very useful to the first researcher for intended future trainings.

The participants also provided feedback about the trainer herself, the first researcher. Those responses were potentially helpful to increasing the effectiveness of future training. They included appreciation of their trainer, citing her as someone who was easy to be with and non-directive, willing to share knowledge, and offering good experience, knowledge, and skills to the training. The findings in Kao and Landreth (1997) noted that instructors' personal teaching style can contribute to the effectiveness of their teaching.

\subsection{Multicultural Perspectives and Considerations}

There were several multicultural perspectives that the first researcher recognized throughout the process that she experienced in Malaysia related to the training. Related to language, the researcher, although Malaysian herself, realized the awkwardness of using Malay language for play therapy for the first time because she had training and practice only using English language in her play therapy work. As a result, she used the nuances of the Malay language for her work. Because Malaysia has three major races, therapists need to consider the uniqueness of each language. Even though Malay is the national language in Malaysia, children below 12 years old may rather speak their own language or English language, and therapist must adapt to individual needs. Hence, the researcher recognized it is important during the communication with child during the play therapy session to be spontaneous 
and natural.

In play therapy, toys are the words for children (Landreth, 2012). It is very important to carefully select the toys that can represent their stories. Malaysia has various races and religious backgrounds, and this fact needs to be considered as well in play therapy. For example, dogs and pigs are restricted in Islam where the Muslim is allowed to make contact, but they need to wash their hand in certain way. However, typically Malay parents do not allow their children to touch a dog and pig. Nevertheless, for other races especially for most Chinese and Indian, they have dogs as pets and eat pork. In similar traditions, the Indian culture, perceives cows as a holy animal. Meanwhile in the Chinese culture exists strong beliefs about the dragon creature. As a result,therapists need to aware of these multicultural differences in the play room. In addition, therapists must consider finding toys that represent Malaysian people, skin colors, foods, animal, dress, etc.. For example, many toys are imported from Western countries, thus it is easy to find baby doll with brown or grey hair but not with black hair.

Furthermore, dealing with parents also can be challenging particularly related to the process of play therapy. Not all parents understand the purpose of certain toys that to be included in the play room. For example, gun, knife, or any aggressive toys are something that Malaysian parents do not allow for their children. For them, these kinds of toys can educate their children to behave aggressively. However, in play therapy, these toys are beneficial to help the child clients express their anger as well as give the child a sense of power and control that may help to build self-esteem. Another example of toy about which there may be strong negative perceptions is sand. While sand is considered a powerful tool in sand tray, for numerous Malaysian parents sand is something "dirty" and not for play.

In summary, the researchers believe the ongoing development and use of play therapy in Malaysia will increase the understanding, acceptance, and appropriate strategies for therapists, parents, and community members regarding the effectiveness in helping their children.

\subsection{Implications}

The findings show how significant the component of training can be in enhancing the competency of mental health professionals, in this case, play therapists (Bratton, Landreth, \& Homeyer, 1993; Porter et al., 2009). Often professionals in a specialized field organize themselves into a professional organization which can develop and manage a system to structure and to further such objectives as enhancing the competency of its members. Play therapists need knowledge and the ability to conduct their therapy effectively (Kao, 2005; Landreth, 2012). To serve clients successfully, they must have had proper training and should have relevant certifications to demonstrate their competence. Continuing training plays an important role in increasing the ability of professionals. This study showed that through training, mental health professionals as participants improved their attitude and increased their knowledge and skill in conducting sessions and helping clients. Without support from an association to initiate and provide this kind of training, the profession can languish, and its practitioners may perform at lower levels.

In addition, it is necessary to have play therapy courses in counseling curricula at the university level. In Malaysia, there are many undergraduate and graduate level counseling programs, but few university courses focus on play therapy. Some programs categorize these courses as merely elective. After graduation, many counseling students plan to work as school counselors or counselors in mental health settings such as hospitals or foster care homes for children. In those settings serve children as clients, counselors who lack training in play therapy are less able to help their clients effectively. To make room for more scholars to enter the play therapy area, university programs need to be prepared with more teachers qualified to teach play therapy. In sum, there is an acute need to offer related courses in university programs which will provide adequate training to bring more professionals into play therapy.

Furthermore, play therapy has a significant impact on family systems. Play therapy for children is analogous to adult talk therapy in counseling. Because of their verbal limitations, play therapy is the best approach to engage in communication to help children with mental health issues. Play therapy encourages involving clients' parents and other family members when appropriate. To do so helps the therapist understands the client's struggles. Thus play therapy is not just conducting sessions with children but also requires skills for parent consultation as well as their orientation to play therapy. Considering the wide variety of mental issues that children have, those working with children should have formal counseling training. In addition, play therapists need continuous training to maintain and expand their competencies and abilities (Bratton et al., 2005). For that reason, continuing education in play therapy at regular intervals should be required for recertification as well as for initial certification.

In conclusion, specific attitude, knowledge, and skills requirements should be mandated before a worker with children can be called a play therapist. Thus, it is very important to have proper training to enhance the capability 
of play therapists and their ethical practice. Malaysia and other countries where play therapy is emerging need to recognize the potential effectiveness of play therapy in helping children with mental health issues. They must also provide training to make sure that play therapy is not misused. Hence, the purpose of this study was to explore and investigate potential benefits of enhanced play therapy training.

\subsection{Limitations}

All participants in this study were volunteer participants who attended the training by their own choice. They had initial interest in play therapy area and work with children before attending the training. Because of their positive attitude and inclination toward play therapy and children, their scores on attitude subscales were already high on the pre test. As a result, the finding with the lowest gain from pre to post was on the attitude subscale compared with knowledge and skills subscales. However, this fact should not be misinterpreted to minimize the importance of proper attitude to practitioners.

Another limitation is the unbalanced numbers of participants. Difficulty in reaching students for the study was one reason for dissimilarity in sizes between the two groups. There were several methods used to reach potential participants including an email list, a website, flyers, and letters to counseling departments. Practitioners were easier to access since the available email list contained a large number of practitioners, but no students. Another reason for the disparity in numbers was that practitioners are in the stage of their careers when they are focusing on advancement as therapists. In contrast, most of students are uncertain about how play therapy can benefit them in view of uncertainty about their career paths.

In addition, this study also compared a group of participants who had had previous play therapy training with a group who had not had any. However, the groups of students and practitioners were defined generally in this study. Additional information related to the students, such as level of education and year of study, were not accessible. Similarly, practitioners' years of experience in the mental health field were not available during the recruiting process. Besides, whether student or practitioner, every member was related to the mental health profession, either in counseling, psychology, social work, or specialized work with children. Due to the impossibility of duplicating the background of the participants, it would be virtually impossible to exactly replicate the experiment, a further limitation.

Lastly, the present study involved two types of learning experiences. The first was theoretical knowledge regarding play therapy including understanding children, play, play therapy, philosophical theories, and basic skills of child-centered play therapy. In this part, participants came to understand the practical application of play therapy. The second part of the training included experiential learning and practice. In this part, participants practiced application of the knowledge gained from the first part by role playing with peers and their instructor. Kits of toys were provided by the researcher for each participant, allowing all the participants to have a chance to take part in the role play. After each role play, there were small- and large group discussions as part of the supervision process. This study emphasized practical issues since a primary objective of the training was to allow the participants to practice competently after the training. Consequently, there was sufficient time allocated in the training to allow participants to work on their practical skills during the training. Thus, based on this study, it was appropriate to complete the training outline in three days but it would have been more effective to have had it longer.

\subsection{Future Research}

This study discovered the usefulness of having short term training for specific sub-categories of professionals such as school or mental health counselors. For example, in Children's Home (RKK) in Malaysia where there are almost three hundred counselors throughout Malaysia who are working with vulnerable children. Another example is in the school setting, particularly elementary school. Courses like play therapy and counseling for children are limited in counseling programs at the university level. Once instituted at the university level, play therapy training will able to equip counselors and mental health professionals to do a better job. This will enhance both the mental health profession and practitioners of the play therapy specialty.

The results of this study suggest including control group in research design and extending Play Therapy training, perhaps into a semester-long course. A study of long term play therapy training (Lindo et al., 2012) on attitude, knowledge and skills for graduate students, show that the long term training has a greater impact on the participants. The training should include varieties of learning processes and more opportunities to develop participants' capability. This intensive training would offer advantages especially for a country of growing need like Malaysia. 


\subsection{Conclusion}

Play therapy has been shown to be a most effective approach to improve mental health in children psychically, emotionally, socially, and cognitively (Landreth, 2001; Ginsburg, 2007). Similar results came from studies to explore the effectiveness of play therapy training in places such as Hong Kong (Siu, 2010), Israel (Kagan \& Landreth, 2009), China (Kao \& Chang, 2007; Shen, 2002; Shen \& Herr, 2003), Australia (Hunt, 2010), as well as Kenya and Tanzania (Hunt, 2006). As a growing practice in Malaysia, play therapy is essential for helping children with mental health problems. See and $\mathrm{Ng}$ (2010) highlighted the need for systematic training in Malaysia as one step to upgrade national mental health. Despite the scarcity of mental health intervention and treatment for children, the present study offers a good start to introduce and promote awareness of the uses and benefits of the play therapy.

Moreover, this study demonstrated that Child-Centered Play Therapy training can significantly help participants enhance their attitude, knowledge, and skills in play therapy. The benefits included enhancement of the participants' careers and improvement in the overall abilities of the mental health profession. Another benefit of this study was to provide the participants with play therapy skills they could practice immediately after the training. Ultimately this study was beneficial to children and parents in Malaysia through the work of the professionals who participated and continue in their effective work.

\section{References}

Bratton, S., Landreth, G., \& Homeyer, L. (1993). An intensive three day play therapy supervision/training model. International Journal of Play Therapy, 2(2), 61-78. http://dx.doi.org/10.1037/h0089366

Bratton, S., Ray, D., Rhine, T., \& Jones, L. (2005). The efficacy of play therapy with children: A meta-analytic review of the outcome research. Professional Psychology: Research and Practice, 36, 375-390. http://dx.doi.org/10.1037/0735-7028.36.4.376

Crabtree, C. S., \& Chong, G. (2000). Mental health and citizenship in Malaysia. International Social Work, 43(2), 217-226. http://dx.doi.org/10.1177/002087280004300207

Creswell, J. W. (2008). Educational Research: Planning, conducting, and evaluating quantitative and qualitative research. Upper Saddle River, NJ: Pearson Education.

Ginsburg, R. K. (2007). The importance of play in promoting healthy child development and maintaining strong parent-child bonds. American Academy of Pediatrics, 182-191.

Homeyer, L. E., \& Rae, A. (1999). Impact of semester length on play therapy training. International Journal of Play Therapy (1555-6824), 7(2), 37. http://dx.doi.org/10.1037/h0089422

Hunt, K. F. (2006). Can professionals offering support to vulnerable children in Kenya benefit from brief Play therapy training? Journal of Psychology in Africa, 16(2), 215-222.

Hunt, K. F. (2010). The impact of brief play therapy training on the emotional awareness of care workers in a young children's residential care setting in Australia. British Journal of Guidance and Counselling, 38(3), 287-299. http://dx.doi.org/10.1080/03069885.2010.492208

Kagan, S., \& Landreth, G. L. (2009). Short-term child-centered play therapy training with school counselors and teachers in Israel. International Journal of Play Therapy, 18(4), 207-216. http://dx.doi.org/10.1037/a0016760

Kao, S. (2005). Play therapy with Asian children. In E. Gil, \& A. Drewes (Eds.), Cultural issues in play therapy (pp.180-194). New York: Guilford.

Kao, S., \& Chang, J. M. (2007). A report on revising the Chinese version of play therapist attitude-knowledge-skills survey. Psychological Testing, 54(1), 121-146.

Kao, S., \& Landreth, G. L. (1997). Evaluating the impact of child-centered play therapy training. International Journal of Play Therapy, 6(2), 1-20. http://dx.doi.org/10.1037/h0089405

Kranz, P., \& Lund, N. L. (1994). Recommendations for supervising play therapists. International Journal of Play Therapy, 3(2), 45-52. http://dx.doi.org/10.1037/h0089168

Kranz, P., Lund, N. L., \& Kottman, T. (1996). Let's play: Inclusion of a play therapy course or program into a graduate curriculum. International Journal of Play Therapy, 5(1), 65-72. http://dx.doi.org/10.1037/h0089328

Landreth, G. L. (2001). Innovations in play therapy: Issues, process, and special populations. New York: 
Brunner-Routledge.

Landreth, G. L. (2012). Play therapy: The art of the relationship (3rd ed.). New York: Brunner-Routledge.

Lindo, N. A., Chung, C-K., Carlson, S., Sullivan, J. M., Akay, S., \& Meany-Walen, K. K. (2012). The impact of child-centered play therapy training on attitude, knowledge, and skills. International Journal of Play Therapy, 21(3), 149-166. http://dx.doi.org/10.1037/a0028039

Porter, M. L., Hernandez-Reif, M., \& Jessee, P. (2009). Play therapy: A review. Early Child Development \& Care, 179(8), 1025-1040. http://dx.doi.org/10.1080/03004430701731613

See, C. M., \& Ng, K. M. (2010). Counseling in Malaysia: History, current status, and future trends. Journal of Counseling \& Development, 88, 18-22. http://dx.doi.org/10.1002/j.1556-6678.2010.tb00144.x

Shen, Y. (2002). Short-term group play therapy with Chinese earthquake victims: Effects on anxiety, depression and adjustment. International Journal of Play Therapy, 11(1), 43-63. http://dx.doi.org/10.1037/h0088856

Shen, Y., \& Herr, E. L. (2003). Perceptions of play therapy in Taiwan: The voices of school counselors and counselor educators. International Journal for the Advancement of Counseling, 25(1), 27-41. http://dx.doi.org/10.1023/A:1024924111194

\section{Copyrights}

Copyright for this article is retained by the author(s), with first publication rights granted to the journal.

This is an open-access article distributed under the terms and conditions of the Creative Commons Attribution license (http://creativecommons.org/licenses/by/3.0/). 